\title{
Bullying as a Correlate of Anxiety among Secondary School Students in Imo State: The Counselling Implications
}

\author{
Bruno U. Onyekuru, C. J. Ugwu* \\ Department of Educational Pyschology, Guidance and Councelling, Faculty of Education, \\ University of Portharcourt, Rivers State, Nigeria \\ *Corresponding author: nelomax2000@yahoo.com
}

\begin{abstract}
This correlational study investigated bullying as a correlate of anxiety among 712 bullied victims in secondary schools in Imo State using purposive random sampling techniques. Four research questions, four hypotheses and two instruments titled: Bullying Victims Identification Questionnaire (BVIQ) and Bullying and Anxiety Relationship Scale (BARS) with test-retest reliability coefficient of 0.71 and 0.72 respectively guided the study. The results showed significant joint and separate positive relationships between physical, verbal, social bullying and social anxiety and test anxiety respectively. It was recommended that school counsellors should develop anti-bullying policies, mount campaigns and organize seminars to actualize free bulling environment in order to enhance academic activities.
\end{abstract}

Keywords: bullying, antisocial behaviour, delinquency, social anxiety, test anxiety

Cite This Article: Bruno U. Onyekuru, and C. J. Ugwu, "Bullying as a Correlate of Anxiety among Secondary School Students in Imo State: The Counselling Implications.” American Journal of Educational Research, vol. 5, no. 1 (2017): 103-108. doi: 10.12691/education-5-1-16.

\section{Introduction}

Many parents cannot forget in a hurry how the joy they experienced on learning that their children were admitted into secondary schools was short-lived when these children returned home after first term and refused to go back. Some of the young students were vocal enough to narrate their ordeals from senior students. Others were dumbfounded and speechless but insisted that they would never go back to "that school". This is especially true for students who lived in hostels or dormitories where senior students ordered them to procure "provisions" for them without giving them money, confiscate their "provisions" and other valuables. Compelled them to sleep under their beds, cut grasses in a v-shaped in the fields and so forth. These activities are some of the iniquities which the young hapless and powerless students contend with daily from the less empathic senior students who never bothered to distinguish between bullying and corrective punishment. The efforts of school principals and teachers in trying to curb bulling through various interventions have not been very successful [36]. Regardless of the grade level, socioeconomic environment, gender, religion or sexual orientation, bullying can happen to anyone, though bullying intensity and prevalence at a given time and place may vary according to some socio-demographic factors [23].

Bullying is a form of aggressive behaviour manifested by the use of force or coercion to affect others particularly when the behaviour is habitual and involves imbalance of power [23]. Olweus [20] defined bullying as repeated negative actions directed at a target over time, where there is a power deferential (real or perceived) between the target and the bully/bullies. According to Ross [28], bullying is an intentional and generally unprovoked attempt by one or more individuals to inflict physical harm and /or psychological distress on one or more victims. It can be deduced from above definitions that bullying behaviour is repeated, or has the potential to be repeated over time. Bulling includes actions such as making threats to someone, spreading rumours against someone, attacking someone physically or verbally, and excluding someone from a group on purpose. For an action to qualify as bullying, there must be power imbalance between the bully and the victim, a repetition of the action and especially unprovoked [23].

Bullying is a serious issue that impacts on the school experience that occur during or after school hours. While bullying occurs in school buses or playground, a significant percentage of bullying occurs in the school buildings especially the dormitory [28]. In the present technological height, internet bullying has begun to rear its ugly head. Students witnessing the act of bullying might avoid intervening or even taunt the victim so as to avoid being targeted by the bully. When one victim is no longer within reach, the bully selects or targets another. Bulling may result to psychological distress and adverse physical symptoms, Rigby and Can as cited in [36].

A survey on school violence in Nigeria conducted by Federal Ministry of Education [11] revealed that physical violence accounted for $85 \%$ of the bulk of violence 
against children in schools. Physical violence was more prevalent in the rural areas (90\%) than in urban centres (80\%), higher in the South (90\%) than in the North (70\%). Psychological violence was $61 \%$ in the south compared to $38.7 \%$ in the North. Owuamanam and Makinwa [23] study of 600 secondary school students in Ondo State revealed that $27.5 \%$ of the sample had been bullied $42.3 \%$ of the sample had bullied other students.

A school is supposed to be a safe haven for children to learn. The students should not be afraid to walk in the halls, or play on the playground just because someone is bent on hurting them and make their lives miserable. The children should be free to go back to school without fear. This is far from reality. Fear of bullying grips students on daily basis. While there is absolutely no excuse for some students trying to harass, intimidate, torment and humiliate others, most bullies have underlying issues that lead to this behaviour. The purpose of this study is to determine the relationship between bulling and anxiety among secondary school students in Imo State of Nigeria.

\subsection{Review of Related Literature}

Bulling and anxiety are two key terms in this study. Both terms are reviewed for better understanding of this paper. Olweus [20] identified three major types of bullying: physical bulling, verbal bullying and social/emotional bullying. These three types of bulling were investigated in this study.

i. Physical bullying: Physical bullying is the act of hurting a person's body or possessions. It basically involves the use of physical force such as hitting, kicking, flogging, shoving, pinching, punching, spitting, tripping/pushing, locking up, taking or damaging someone's property, making mean or rude hand gestures, extortion, confiscation of someone's property, etc. The idea behind physical bullying is for the bully to establish superiority and continued control over a victim. Physical bullying is more likely to occur among males [21].

ii. Verbal bullying: Verbal bullying is an act of saying or writing demeaning things about someone with the intent of hurting the person's ego or feelings [13]. In this type of bullying, the aggressor tries to verbally upset the victim through teasing, name-calling, inappropriate sexual comments, taunting, threat to cause harm to someone, derogatory remakes, etc. The verbal assault may focus on an individual's appearance, lifestyle choices, intellect, skin colour or ethnicity. In most cases, verbal bullying is the province of girls. Girls use more subtle and verbal bullying as well as social exclusion techniques to dominate others and show their superiority and power. Verbal bullying is hinged on the premise that words are powerful and can bring about emotional consequences, even if the aggressor never lays a finger on the victim. Most verbal bullies have a low self-esteem and tend to bully others so as to bolster or boost their ego, their social standing and to feel better about themselves and their accomplishment.

iii. Social/emotional bullying: Social bullying is referred to as relational bullying. It is an act of intentional hurting of someone's reputation or relationships [20]. Social bullying is mostly common in relationships whereby a bully may make statements or act in such a manner to bring about distress to the victim through rumours, deliberately excluding someone from a group or certain activities, telling other children not to be friends with someone, embarrassing someone in public, refusing to talk to someone and even making statement with an intention to hurt a person's feelings in public, social bulling fits into Olweus [20] concept of indirect bullying consisting of social isolation and exclusion from groups. Indirect bullying is a social aggression characterized by attempt to socially isolate a victim [29].

Consequences of bullying: The consequences of bullying are disastrous and can be felt by the victims, the observers, the bullies themselves and the school at large. Students who are bullied can develop physical symptoms such as headaches or stomach pains and fear for school. They are more likely to fell disconnected from school, not like school or skip classes. They often have difficulty concentrating on their academic work and their performance tends to move from "marginal to poor" [3]. Bullied students often lack quality friends at school and display high levels of emotion that indicate vulnerability and low levels of resilience [20]. They avoid conflict are socially withdrawn and rates of substance abuse, truancy and drop-out are higher among victimized students than among non-bullied peers [22]. Rigby and Slee [27] observed that youths who are bullied generally show high level of insecurity, anxiety, depression, loneliness, unhappiness, physical and mental symptoms and low selfesteem.

\subsection{Anxiety}

Anxiety is regarded as a general term for several disorders that cause nervousness, fear, apprehension and worry [6]. Seligman, Walker and Rosenhan [32] defined anxiety as an unpleasant state of inner turmoil often accompanied by nervous behaviours such as pacing back and forth, somatic complaint and rumination. It is a feeling of worry, dread and uneasiness which people have as a result of over-reaction to a situation that is subjectively seen as menacing. Anxiety when it is mild is normal and helps to invigorate an individual and prepares the body physically, cognitively and behaviourly to detect and deal decisively with threats to survival, but severe anxiety can be extremely debilitating having serious impact on daily lives.

Test anxiety, is synonymous with anticipatory anxiety, performance anxiety, situational anxiety, and evaluation anxiety. Zeidner [37] defined test anxiety as a combination of perceived physiological over-arousal, feeling of worry and dread, self-depreciating thoughts, tension and somatic symptoms that occur during test situations. It was defined by Karatas, Alci and Aydin [16] as subjective emotional state experienced before or during a specific evaluation relating to the act of completing the evaluation itself, the threat of failing and the perceived negative consequences. It can also be seen as a physiological condition in which people experience extreme stress, and discomfort during and/or before taking a test. Test anxiety is an uneasiness or apprehension experienced before, during or after examination because of concern, worry or fear of uncertainty. It was defined by Zeidner [37] as a set of phenomenological, physiological 
and behavioural responses that accompany concern about possible negative consequences or failure in an examination or similar evaluative situation. It is a feeling that someone might have in a situation where performance really counts or where the pressure to do well is intense.

Pioneering work on test anxiety was credited to George Mandler and Seymour Sarason [17] during which they investigated the reasons why students prepared for examinations but failed to perform when it mattered most. Test anxiety is subjective and dependent upon situational variables such as levels of motivation, task complexity and practical consequences of high or low performance, and it varies markedly from one person to another. Extreme test anxiety leads to a vicious cycle of low selfesteem, depression, anger and feeling of hopelessness and poor academic grade [37]. Repeated poor academic grade may lead to increased test anxiety and ultimately to a dropout [37].

Causes of test anxiety among students as outlined by Salend [30] include fear of failure, procrastination for test preparation, unhealthy school environment such as cultism, violence, vices, bullying, etc. Others include previous poor test performance, low self-confidence as well as characteristics of test environment such as nature of the task, level of difficulty of the task, atmosphere, time constraints, examiner characteristics, mode of test administration and physical setting. Researchers reported that between 25 to 40 percent of students experience test anxiety [7]. Twenty percent of test-anxious students quit school before graduating because of repeated academic failures [35]. Hembree [14] noted that 30\% of students suffer from test anxiety and that high test anxiety is associated with low self-esteem, poor reading and mathematics achievement, failing grades, disruptive classroom behaviours, negative attitudes toward school, and unpleasant feelings of nervousness and dread that stem from an intense fear of failure. Sena, Lowe and Lee [33] found that students with higher test anxiety obtain lower marks in examination. Chapell, Blanding, Siverstein, Takashi, Newman, Gubi and Mccain [8] found a significant inverse relationship between test anxiety and grade point average among the students.

Social anxiety is defined as a chronic fear of social situations that put one in the position of evaluation by others $[4,9]$. Individuals with social anxiety often fear that they will embarrass themselves in front of other people or that they will be scrutinized. They doubt their ability to make a good impression on others. Due to these fears, socially anxious individuals are likely to avoid social events that are likely to provoke the disorder's symptoms [2]. While the most common fear reported in those with social anxiety is public speech, other situations that cause distress include eating in public, attending parties, speaking in group meetings, going on dates, and starting conversations [2]. However, social anxiety is more than a basic fear of being negatively evaluated. Individuals with social anxiety see themselves more negatively, are more likely to remember unsuccessful social situation and blame themselves for the outcome, and are more prone to perceiving social events in a negative way, even when they are wrong [9]. Rather than a contributing source to the social world, a person with social anxiety sees himself or herself as a powerless objects placed in the middle of a social situation. While those who are socially anxious realize that their fears are unreasonable and exaggerated, their own thoughts and actions keep them as victims to the anxiety [12].

\section{Method}

From 585 registered secondary schools in the 27 local government areas of Imo State (Source: Statistics Unit, Imo State Ministry of Education, Owerri; 2014), 32 schools were selected for the study using purposive sampling technique as some schools have zero tolerance for bullying. Then through simple random sampling technique, a total of 3840 JSS1, JSS2, JSS3 and SS1 students were pre-tested to ascertain those who were victims of bullying using self-structured questionnaire titled: Bullying Victims Identification Questionnaire (BVIQ). This instrument contained 15 items of 4-point response format of strongly agree, agree, disagree and strongly disagree with a maximum of 60 points. A student who scored above 30 points from the (BVIQ) was adjudged as a victim of bullying and fit for the study. A total of 894 students were identified as victims of bullying. However, 712 victims participated successfully in the study. Bullying and Anxiety Relationship Scale (BARS) had three sections. Section A obtained demographic information. Section B measured the extent of bullying with subsections on physical, verbal and social bullying. Each subsection contained 5 items with 4-point response format of strongly agree, agree, disagree and strongly disagree giving a minimum point of 5 and maximum point of 20. Section $C$ measured the extent of anxiety. It had two subsections. The first subsection was on social anxiety while the second subsection was on test anxiety. Each of these subsections contained 8 items with 4-point response format of strongly agree, agree, disagree and strongly disagree with minimum point of 8 in each subsection and the maximum point of 32 .

Through test re-test method a reliability coefficients of 0.72 for (BARS) and 0.71 for (BVIQ) were obtained respectively. The data obtained were analyzed using SPSS (version 21) and the results shown below.

\subsection{Research Questions and Hypotheses}

Four research questions and four hypotheses guided the study.

$\mathbf{R q}_{1}$ : What is the joint relationship between bullying (physical, verbal and social) and social anxiety?

$\mathbf{R q}_{2}$ : What is the separate relationship between bullying (physical, verbal and social) and social anxiety?

$\mathbf{R q}_{3}$ : What is the joint relationship between bullying (physical, verbal and social) and test anxiety?

$\mathbf{R} \mathbf{q}_{4}$ : What is the separate relationship between bullying (physical, verbal and social) and test anxiety?

$\mathbf{H o}_{1}$ : There is no significant joint relationship between bullying (physical, verbal and social) and social anxiety.

$\mathbf{H o}_{2}$ : Significant separate relationship between bullying (physical, verbal and social) and social anxiety does not exist.

$\mathbf{H o}_{3}$ : There is no significant joint relationship between bullying (physical, verbal and social) and test anxiety. 
$\mathbf{H o}_{4}$ : Significant separate relationship between bullying (physical, verbal and social) and test anxiety does not exist.

\section{Results}

$\mathbf{R q}_{1}$ : What is the joint relationship between bullying (physical, verbal and social) and social anxiety?

The data generated from the instrument were used to answer the research question, using Pearson coefficient of correlation associated with multiple regression analysis. The results are as shown in Table 1.

Table 1. R-values from multiple regression analysis for joint relationship between bullying and social anxiety

\begin{tabular}{cccc}
\hline $\mathrm{R}$ & R-Square & Adjusted R-Square & \\
\hline & 0.696 & 0.484 & 0.482 \\
\hline
\end{tabular}

Table 1 shows that the Pearson correlation coefficient (r) for joint relationship between bullying (physical, verbal and social) and social anxiety is 0.696 . The value of r-square is 0.484 while the adjusted r-value is 0.482 . The r-value of 0.696 implies that there is a high positive joint relationship between bullying and social anxiety. The adjusted r-value of 0.482 shows that $48.2 \%$ of variation in social anxiety can be explained by the joint action of physical, verbal and emotional bullying, while the remaining $51.8 \%$ may be accounted for by the variables not investigated in this study.

$\mathbf{H o}_{1}$ : There is no significant joint relationship between bullying (physical, verbal and social) and social anxiety.

Hypothesis one was tested using analysis of variance associated with multiple regression analysis. The results obtained are as shown in Table 2.

Table 2 shows that the calculated f-ratio is 221.177 while the critical f-ratio at 3 and 708 degrees of freedom and 0.05 alpha level is 2.615. Since the calculated f-ratio is greater than the critical f-ratio, the null hypothesis was rejected. This implies that there is a significant joint relationship between bullying (physical, verbal and emotional) and social anxiety. This means that physical bullying, verbal bullying and social bullying have a significant combined relationship with social anxiety.

$\mathbf{R q}_{2}$ : What is the separate relationship between bullying (physical, verbal and social) and social anxiety? And $\mathbf{H o}_{2}$ :
Significant separate relationship between bullying (physical, verbal and social) and social anxiety does not exist. Data for research question two and its corresponding hypothesis were analyzed using standardized beta coefficients and t-test. The results obtained are as shown in Table 3 .

The results in Table 3 reveal that the individual regression coefficients represented by standardized beta coefficients are $0.307,0.262$ and 0.180 for physical, verbal and emotional bullying respectively. This implies that there is a low positive relationship between each of physical bullying, verbal bullying and emotional bullying and social anxiety. Physical bullying has the greatest positive relationship with social anxiety, verbal bullying has the second greatest positive relationship with social anxiety while social bullying has the third greatest positive relationship with social anxiety. The model equation relating physical bullying, verbal bullying and social bullying to social anxiety is given by $\mathrm{Y}=8.785+0.468 \mathrm{x}_{1}+0.338 \mathrm{x}_{2}+0.286 \mathrm{x}_{3}$, where $\mathrm{Y}$ is social anxiety, $x_{1}$ is physical bullying, $x_{2}$ is verbal bullying while $\mathrm{x}_{3}$ is social bullying.

Table 3 also shows that the t-values for physical bullying, verbal bullying and emotional bullying are 6.491, 5.227 and 3.595 respectively. Each of these types of bullying has significant relationship with social anxiety at 0.00 probability level which is less than 0.05 probability level. Hence, physical bullying, verbal bullying and emotional bullying each has significant relationship with social anxiety at 0.05 .

$\mathbf{R q}_{3}$ : What is the joint relationship between bullying (physical, verbal and social) and test anxiety?

Data for research question three were analyzed by the use of Pearson coefficient of correlation associated with multiple regression analysis. The results are as shown in Table 4 below.

Table 4 shows that the r-value is 0.854 , the r-square value is 0.729 while the adjusted r-square value is 0.728 . Based on the r-value of 0.854 , it can be inferred that there is a high positive joint relationship between bullying (physical, verbal and emotional) and test anxiety. On the basis of the adjusted r-value of 0.728 , an inference that can be drawn is that $72.8 \%$ of variation in test anxiety can be explained by the joint action of physical, verbal and emotional bullying, while the remaining $27.2 \%$ may be accounted for by the variables not investigated in this study.

Table 2. Summary of results of ANOVA associated with multiple regression analysis

\begin{tabular}{lccccc}
\hline Source of variance & Sum of square & $\mathrm{df}$ & Mean square & $\mathrm{F}_{\text {cal }}$ & $\mathrm{F}_{\text {crit }}$ \\
\hline Regression & 2535.837 & 3 & 845.279 & 221.177 & 2.615 \\
Residual & 2705.791 & 708 & 3.822 & & \\
Total & 5241.628 & 711 & & & \\
\hline
\end{tabular}

Table 3. Relative relationship between types of bullying and the social anxiety

\begin{tabular}{|c|c|c|c|c|c|}
\hline \multirow[t]{2}{*}{ Variables } & Unstandardized coefficient & Stand. coeff. & $\mathrm{t}$ & sig. & \\
\hline & B & Std. error & Beta & & \\
\hline Constant & 8.785 & 0.580 & & 15.146 & 0.000 \\
\hline PHYSICAL BULLYING & 0.468 & 0.072 & 0.307 & 6.491 & 0.000 \\
\hline VERBAL BULLYING & 0.338 & 0.065 & 0.262 & 5.227 & 0.000 \\
\hline SOCIAL BULLYING & 0.286 & 0.080 & 0.180 & 3.595 & 0.000 \\
\hline
\end{tabular}


Table 4. R-values from multiple regression analysis for joint relationship between bullying and test anxiety

\begin{tabular}{ccc}
\hline $\mathrm{R}$ & R-Square & Adjusted R-Square \\
\hline 0.854 & 0.729 & 0.728 \\
\hline
\end{tabular}

$\mathbf{H o}_{3}$ : There is no significant joint relationship between bullying (physical, verbal and social) and test anxiety.

Data for hypothesis three were analyzed using analysis of variance associated with multiple regression analysis. The results are as shown in Table 5 below.

Table 5 shows that the calculated f-ratio is 636.083 while the critical f-ratio obtained at 3 and 708 degrees of freedom and alpha level of 0.05 is 2.615. Since the calculated f-ratio is greater than the critical f-ratio, the null hypothesis was rejected. This implies that there is a significant joint relationship between bullying (physical, verbal and social) and test anxiety.

$\mathbf{R q}_{\mathbf{4}}$ : What is the separate relationship between bullying (physical, verbal and social) and test anxiety? And Ho4: Significant separate relationship between bullying (physical, verbal and social) and test anxiety does not exist.

Data for research question four and its corresponding hypothesis were analyzed using standardized beta coefficients and t-test. The results obtained are as shown in Table 6 below.

Table 6 shows the standardized beta coefficients for the individual relationship between types of bullying and test anxiety. The standardized beta coefficients for physical bullying, verbal bullying and social bullying are 0.215 , 0.509 and 188 respectively. This implies that physical bullying has low positive relationship with test anxiety, verbal bullying has moderate positive relationship with test anxiety while social bullying also has low positive relationship with test anxiety. The model equation describing the relationship between these bullying types and test anxiety is $\mathrm{Y}=6.778+0.316 \mathrm{x}_{1}+0.635 \mathrm{x}_{2}+0.289 \mathrm{x}_{3}$, where $\mathrm{Y}$ is test anxiety, $\mathrm{x}_{1}$ is physical bullying, $\mathrm{x}_{2}$ is verbal bullying while $\mathrm{x}_{3}$ is social bullying.

The t-values of 6.270, 14.001 and 5.196 were obtained for physical bullying, verbal bullying and social bullying respectively. These t-values are all significant at 0.00 alpha level. Since, 0.05 is greater than 0.00 , it implies that the t-values are also significant at 0.05 alpha level. Hence, the null hypothesis was rejected. Therefore, significant separate relationship between each of physical bullying, verbal bullying and social bullying and test anxiety exists.

Table 5. Summary of results of ANOVA associated with multiple regression analysis

\begin{tabular}{lcccc}
\hline Source of variance & Sum of square & df & Mean square & $F_{\text {cal }}$ \\
\hline Regression & 3575.019 & 3 & 1191.673 & 636.083 \\
Residual & 1326.406 & 708 & 1.873 & \\
Total & 4901.426 & 711 & & \\
\hline
\end{tabular}

Table 6. Relative relationship between types of bullying and the test anxiety

\begin{tabular}{|c|c|c|c|c|c|}
\hline Variables & $\begin{array}{c}\text { Unstandardized coefficient } \\
\text { B }\end{array}$ & $\begin{array}{l}\text { Stand. coeff. } \\
\text { Std. error }\end{array}$ & $\begin{array}{c}\mathrm{t} \\
\text { Beta }\end{array}$ & sig. & \\
\hline Constant & 6.778 & 0.406 & & 16.690 & 0.000 \\
\hline PHYSICAL BULLYING & 0.316 & 0.050 & 0.215 & 6.270 & 0.000 \\
\hline VERBAL BULLYING & 0.635 & 0.045 & 0.509 & 14.001 & 0.000 \\
\hline SOCIAL BULLYING & 0.289 & 0.056 & 0.188 & 5.196 & 0.000 \\
\hline
\end{tabular}

\section{Discussion of Findings}

There was a significant joint and positive relationship between bullying (physical, verbal and social) and social anxiety. It was also found that a significant separate and positive relationship between each of physical bullying, verbal bullying, social bullying and social anxiety respectively. These findings are in agreement with the findings of Gopalakrishan and Sundram [12] who found both positive joint relationship exist between cyber bullying and social anxiety, and separate positive relationship between cyber victimization and social anxiety. A positive relationship between bullying and social anxiety can be explained from the fact that both victims of bullying and socially anxious persons see themselves as powerless and appear to be defenseless.

Results indicate a significant joint and positive relationship between bullying (physical, verbal and social) and test anxiety. That there was a significant separate and positive relationship between each of physical bullying, verbal bullying social bullying and test anxiety respectively. These findings are similar to the findings of Simpson [34] which revealed that antisocial behaviours including pilfering, addiction to smoking and rule infractions correlated positively and significantly with test anxiety. The positive and significant joint relationship with test anxiety could be explained from the fact that victims of bullying lack self-confidence which is an essential ingredient required for test writing.

\section{Conclusion}

The inference that can be drawn from this study is that bullying has far-reaching consequences. The three types of bullying which include physical bullying, verbal bullying, and social bullying correlate positively, jointly, individually and significantly with each of social anxiety and test anxiety in this study.

\section{Counselling Implications}

Bullying among the students impacts negatively on the emotions and psych of the students and by extension on the academic achievement of the students. Anxiety itself is often a consequence of some factors including bullying 
and violence meted out to the students. A high rate of bullying among the students which precipitates anxiety which in turn hampers their academic activities is a pointer to the dereliction of duties by school staff and management including counsellors.

School counsellors must be up and doing if they must assist the school authority to win the war against bullying and vices in school. The school counsellor should help to create awareness on bullying so that students are able to distinguish between bullying and punishment. Ignorance of bullying by prospective student-victims is capable of compelling the students to submit to bullying rather than making protective efforts. School counsellors should do more to help the students understand when they are bullied and encourage them to report all acts of bullying to school authority.

Counsellors should encourage the school authority to mount vigorous campaigns against bullying so as to create a conducive environment in the school for teaching and learning to thrive. When resources permit, counsellors should liaise with school authority to organize seminars on bullying, its effects and ways to curb it. They should also assist the school in production of suitable stickers and fliers to discourage bullying behaviours in schools.

The counsellors can also assist the school authority to develop anti-bullying policies which must be actively implemented to discourage bullying. School counsellors with their wealth of experience should help to draft curriculum on compassion and empathy suitable for primary and secondary school students in bullying-endemic schools. Students should be made to take lessons on compassion and empathy so as to imbibe pro-social values.

\section{References}

[1] Aluede, O. (2006). Bullying in schools: A form of child abuse in schools education Research Quarterly, 30(1), 37-49.

[2] American Psychiatric Association (2000). Diagnostic and statistical manual of mental disorder. Washington, DC: Author Publishers.

[3] Ballard, M., Tucky; A \& Remely, T. P. (1999). Bullying and violence: A proposed intervention programme. NASSP Bulletin, 38-47.

[4] Barlow, D. H. (2002). Anxiety and its disorder: The nature and treatment of anxiety and panic. ( $2^{\text {nd }}$ Ed.). New York: Guilford Press.

[5] Birjandi, P. \& Alemi, M. (2010). The impact of test anxiety on test performance among Iranian EFL learners' brain. Broad Research in Artificial Intelligence and Neuroscience. 1 (4) 45-68.

[6] Bouras, N. \& Holt, G. (2007). Psychiatric and behavioural disorder in intelligence and developmental disabilities ( $2^{\text {nd }}$ ed). England: Cambridge University Press.

[7] Cassady, J. C. \& Johnson, R. E. (2002). Cognitive test anxiety and academic performance Contemporary Educational Psychology. 27 (2) 274-295.

[8] Chapell, M. S. Blanding, Z. B., Siverstain, M. E., Takashi, M. N. B., Newman, B., Gubi, A. \& Mccain, N. (2005). Test anxiety and academic performance in undergraduate and graduate students. Journal of Educational Psychology, 97 (2), 268-274.

[9] Craske, M. G. (1999). Anxiety disorders: Psychological approaches to theory and treatment. Boulder, CO: Westview Press.

[10] Decaro, M. S., Thomas, R. D. Albert, N. B. \& Beilock, S. L. (2011). Choking under pressure: Multiple routes to skill failure. Journal of Experimental Psychology and Genetics. 140 (3), 390-406.

[11] Federal Ministry of Education (2007). The national strategic framework for violence free basic education in Nigeria. Abuja: Federal Ministry of Education.
[12] Gopalakrishnan, S. K. \& Sundram, S. (2014). Cyber bullying victimization and social anxiety among secondary school students. International Journal of Current Research and Academic Review. 2 (10), 55-59.

[13] Gradin, K. G. \& Hammarrstrom, A. (2005). A possible contributor to the higher degree of girls reporting psychological symptoms compared with boys in grade nine. European Journal of Public Health, 15, 380-385.

[14] Hembree, R. (1998). Correlates, causes and treatment of test anxiety. Review of Educational Research. 58 (1) 47-77.

[15] Jones, L. \& Petruzzi, D.C. (1995): Test anxiety: A review of theory and current treatment. Journal of College Student Psychotherapy. 10 (1), 3-15.

[16] Karatas, H, Alci, B. \& Aydin, H. (2013). Correlation among high school senior students' test anxiety, academic performance and points of university entrance exam. Review of Educational Research. 58 (3) 47-77.

[17] Mandler, G. \& Sarason S. B. (1952). A study of anxiety and learning. Journal of Abnormal and Social Psychology, 47 (5), 166-173.

[18] Nicaise, M. (1995). Treating test anxiety: A review of three approaches. Teacher Educational Practices. 22 (7) 65-81.

[19] Oliver, R., Hoover, J. H. \& Hazler, R. (1994). The perceived roles of bullying in small-town Midwestern schools. Journal of Counselling and Development, 72(4), 416-419.

[20] Olweus, D. (1993). Bully/victim problems among school children: Long-term consequences and an effective intervention programme. In S. Hodgins (Ed.). Mental disorder and crime. Newbury Park, C.A: Sage.

[21] Olweus, D. (2003). A profile of bullying in schools. Educational Leadership, 60 (6), 12-17.

[22] Omoteso, B. A. (2010). Bullying behaviour, its associated factors and psychological effects among secondary students in Nigeria. The Journal of International Social Research, 3 (10), 498-509.

[23] Owuamanam, D. \& Makinwa, V. I. (2015). Prevalence of bullying among secondary school students in Ondo State, Nigeria. European Scientific Journal, 11 (20), 326-333.

[24] Pepler, D. J. \& Craig, W. M. (2000). Victims turn aggressors: Factors in the development, making a difference, recognizing and preventing bullying. National Resource Centre for safe schools.

[25] Putwain, D. W., Woods, K. A. \& Symes, W. (2010). Personal and situational predictors of test anxiety of students in post-compulsory education. British Journal of Educational Psychology. 80,137-160

[26] Rezazadah, M, \& Tavakoli, M. (2009). Investigating the relationship among test anxiety, gender academic achievement and years of study: A case of Iranian EFL University students. English Language Teaching, 2 (4), 68-74.

[27] Rigby, K. \&. Slee, P. T. (1991). Bullying among australian school children: Reported behaviour and attitudes toward victims. Journal of Social Psychology, 131(5), 615-627.

[28] Ross, D. M. (2003). Childhood bullying, teasing and violence: What school personnel, other professionals and parents can do. Alexandria, VA: American Counselling.

[29] Ross, P. N. (1998). Arresting violence: A resource guide for schools and their communities Toronto: Ontario Public school Teachers Federation.

[30] Salend, S. J. (2012). Teaching students not to sweat the test. Phi Delta Kappan. 93 (6), 20-25.

[31] Sarason, I.G. (1960). Empirical findings and theoretical problems in the use of anxiety scales. Psychological Bulletin. 57, 403-415.

[32] Seligman, M. F., Walker, E. F. \& Resenhan, D. L. (2010). Abnormal psychology (4 ${ }^{\text {th }}$ ed). New York: W.W. Norton \& Company.

[33] Sena, J. D. Lowe, P. A. \& Lee, S.W. (2007). Significant predictors of test anxiety among students with and without learning disabilities. Journal of Learning Disabilities, 40 (4), 360-376

[34] Simpson, L. (2007). Antisocial behaviours as correlates of test anxiety among college students. Journal of Abnormal Psychology, 11 (7) 85-101.

[35] Tobias, S. (1979). Anxiety research in educational psychology. Journal of Educational Psychology, 71(8), 573-582.

[36] Ugwu, C. J. \& Olatunbosun, I. (2016). Effects of cognitive behaviour therapy on reducing bulling on secondary school students in Ikwere local government area, Rivers State. The Counsellor, 35 (2), 174-183.

[37] Zeidner, M. (1998). Test anxiety: The state of the art: New York: Plenum Press. 